\title{
MULTIPLE REGRESSION ANALYSIS OF EFFECTS OF BAR AND TIDE ON SHORELINE CHANGE
}

\author{
Masayuki BANNO $^{1}$ and Yoshiaki KURIYAMA ${ }^{1}$
}

\begin{abstract}
The effects of bars and tides on shoreline change were investigated by a multiple regression analysis. The shoreline change rates used for the analysis were estimated from the beach profiles measured every workday during a 22-year period from 1986 to 2007 on the Hasaki coast in Japan. The examined parameters which had the potential to affect shoreline change rates were offshore wave energy fluxes, previous shoreline positions, maximum, minimum and average tides, and inner and outer bar crest elevations. In the multiple regression analysis, parameters which affected the shoreline change rate were selected by comparing the multiple regression models developed by combining the parameters on the basis of the Akaike Information Criterion (AIC) value, and the effects were also estimated by using the coefficients of the best model which had the smallest AIC. The shoreline change was affected by not only the offshore wave energy fluxes and the previous shoreline positions but also the maximum and minimum tides and the inner and outer bar crest elevations. The largest effect was the offshore wave energy fluxes, followed in order by the maximum tides, the previous shoreline positions, the minimum tides, the outer bar crest elevations and the inner bar crest elevations.
\end{abstract}

Keywords: shoreline change; multiple regression analysis; Akaike Information Criterion

\section{INTRODUCTION}

Beach erosion is on the rise in many places around the world and has become a problem. Beach erosion is expected to be exacerbated by the rise in sea level and extraordinary tropical cyclones due to global warming. In order to estimate the shoreline change due to global warming and investigate countermeasures, a model for predicting long-term shoreline changes is required.

Several models were developed for predicting shoreline change caused by cross-shore sediment transport (e.g. Yates et al. 2009, Miller and Dean 2004, Katoh and Yanagishima 1988, Davidson et al. 2010). Those models assumed that the shoreline change rates could be expressed by the wave energy and the shoreline position. The shoreline position used as an explanatory variable had a function that the beaches that had already advanced or eroded largely tend to recover to their original state, which results from the equilibrium beach profile in wave energy. For example, the function shows that the further the shoreline position retreats, the more shoreline positions tend to advance, and vice versa.

Thus, it is well known that the shoreline change rate caused by cross-shore sediment transport is affected by wave energy flux. However, the influences of bars and tides are not fully understood and are not considered sufficiently in those shoreline prediction models, although the longshore bar crest elevations and the tidal levels are considered to affect the shoreline change rate by dissipating the wave energy due to the wave breaking. In this study, the effects of bars and tides on shoreline changes were investigated using multiple regression models and a 22-year field data set from 1986 to 2007.

\section{METHODS}

\section{Field Survey and Measurement}

The beach profile data were obtained at the Hazaki Oceanographical Research Station (HORS) located about $4 \mathrm{~km}$ from the north edge of the Hasaki coast facing the Pacific Ocean in Japan (Figure 1). The coast consists of a 16-km sandy beach stretching from Kashima Port in the north to Hasaki fishery harbor in the south. The sediment volume of this coast was assumed to be approximately stable.

\footnotetext{
${ }^{1}$ The Port and Airport Research Institute, 3-1-1 Nagase, Yokosuka, Kanagawa, 239-0836, JAPAN
} 


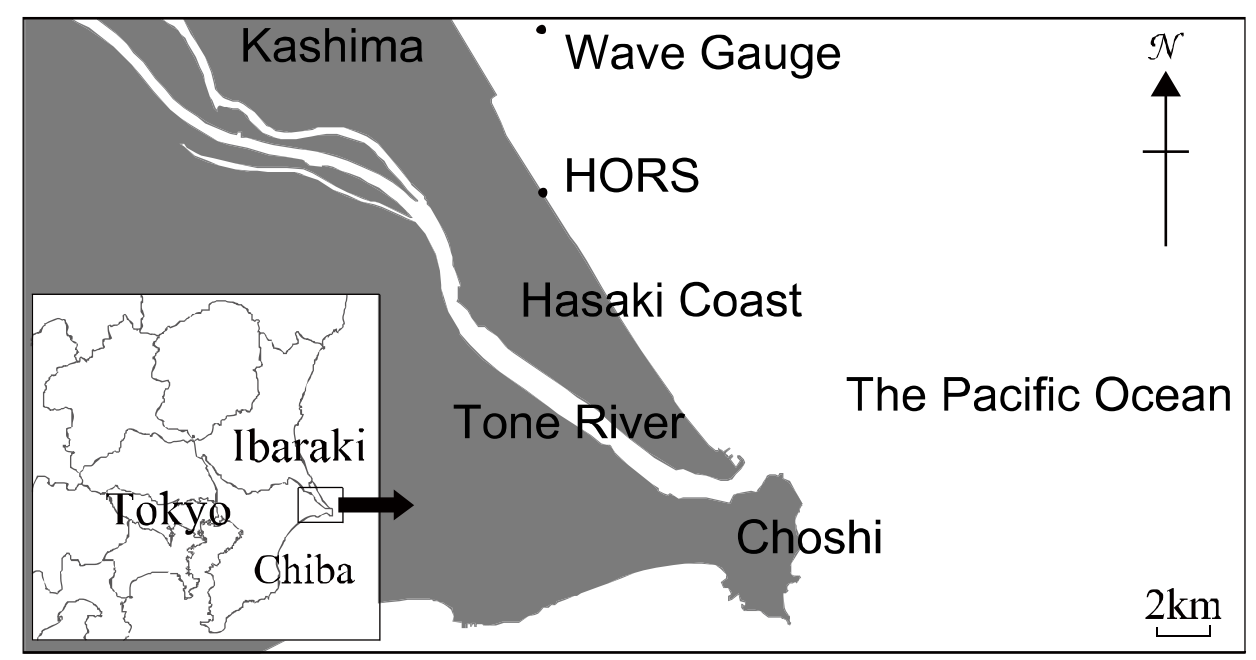

Figure 1. The locations of Hasaki beach and HORS in Japan.

HORS has a 427-m-long pier (Photo 1) and the beach profiles (Figure 2) have been measured at 5$\mathrm{m}$ intervals along the pier every workday since 1986 with a $5-\mathrm{kg}$ lead from the pier and with a level and a staff on the land side. The average beach profile during the investigation period shows that the mean beach slope was about 0.02 (Figure 3) and the mean diameter of sediments around HORS was $0.18 \mathrm{~mm}$. The bathymetry around HORS was nearly uniform alongshore (Kuriyama 2002), and thus the shoreline change was assumed to be mainly caused by cross-shore sediment transport. The shoreline positions at H.W.L. detected from the beach profiles (see Figure 2) were used for the analysis. The seaward direction was defined to be positive.

Offshore waves were measured at a water depth of about $24 \mathrm{~m}$ near HORS (see Figure 1) with an ultrasonic wave gauge for 20 minutes every 2 hours, and tides were measured in Kashima Port. The average offshore significant wave height and period during the investigation period were $1.34 \mathrm{~m}$ and $8.00 \mathrm{~s}$ (Figure 4), respectively. The monthly means of the offshore significant wave height and period are shown in Figure 5. The wave heights from February to April and from September to October are high owing to extratropical cyclones and typhoons, respectively. On the other hand, the wave heights from May to August are relatively small. The tidal levels at L.W.L., M.W.L. and H.W.L. were $-0.20 \mathrm{~m}$ $0.65 \mathrm{~m}$ and $1.25 \mathrm{~m}$ from the datum line (Tokyo Peil $-0.69 \mathrm{~m}$ ), respectively. The missing data of the waves and tides were filled by the estimated values from another wave gauge located at about $60 \mathrm{~km}$ north of HORS and the predicted tidal levels.

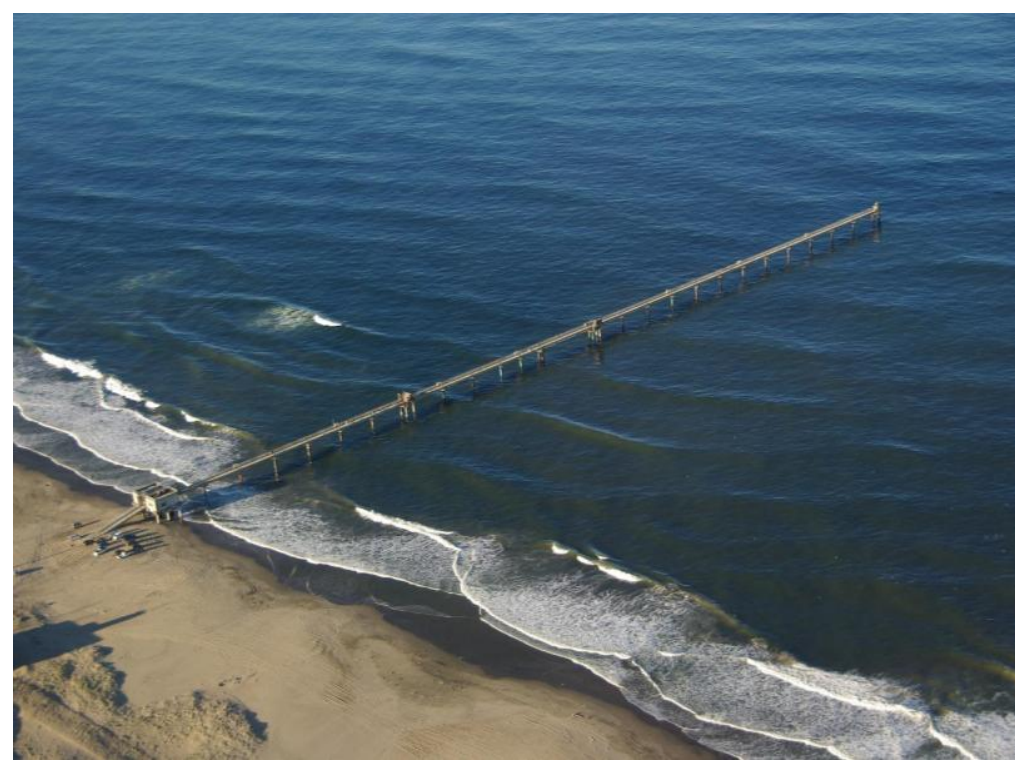

Photo 1. The pier at Hazaki Oceanographical Research Station. 


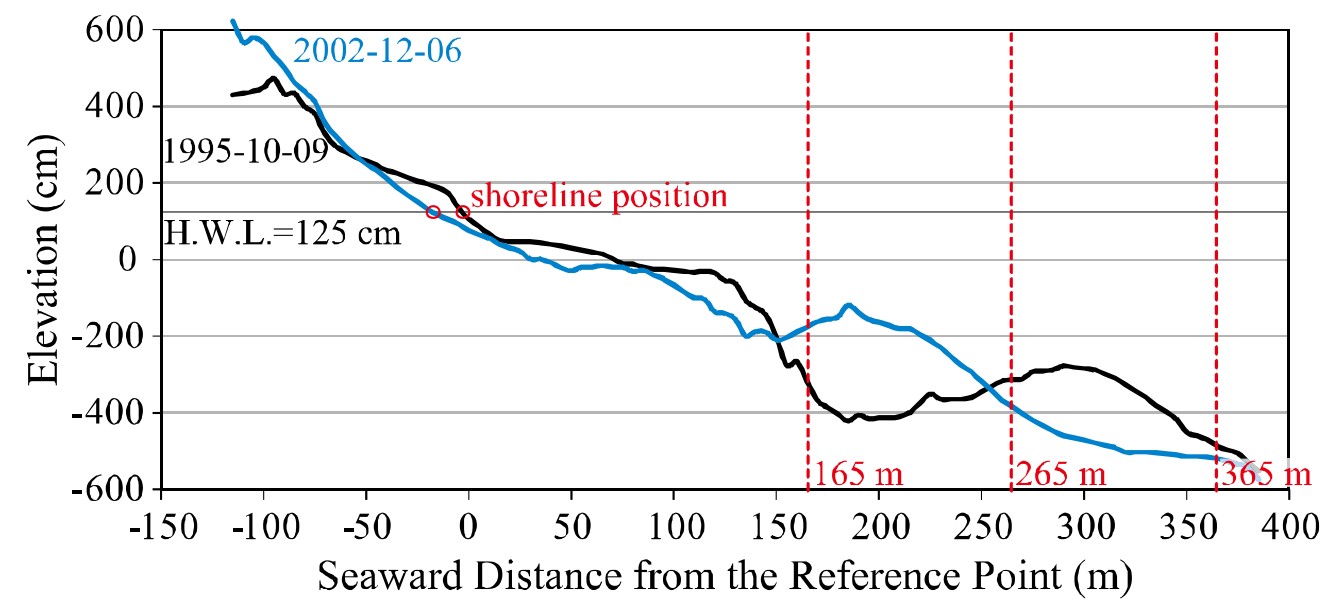

Figure 2. Examples of measured profiles. Circles show the shoreline positions and the vertical broken lines show the zone boundaries used for the definitions of the bar crest elevations, of which the seaward distances were $165 \mathrm{~m}, 265 \mathrm{~m}$ and $365 \mathrm{~m}$.

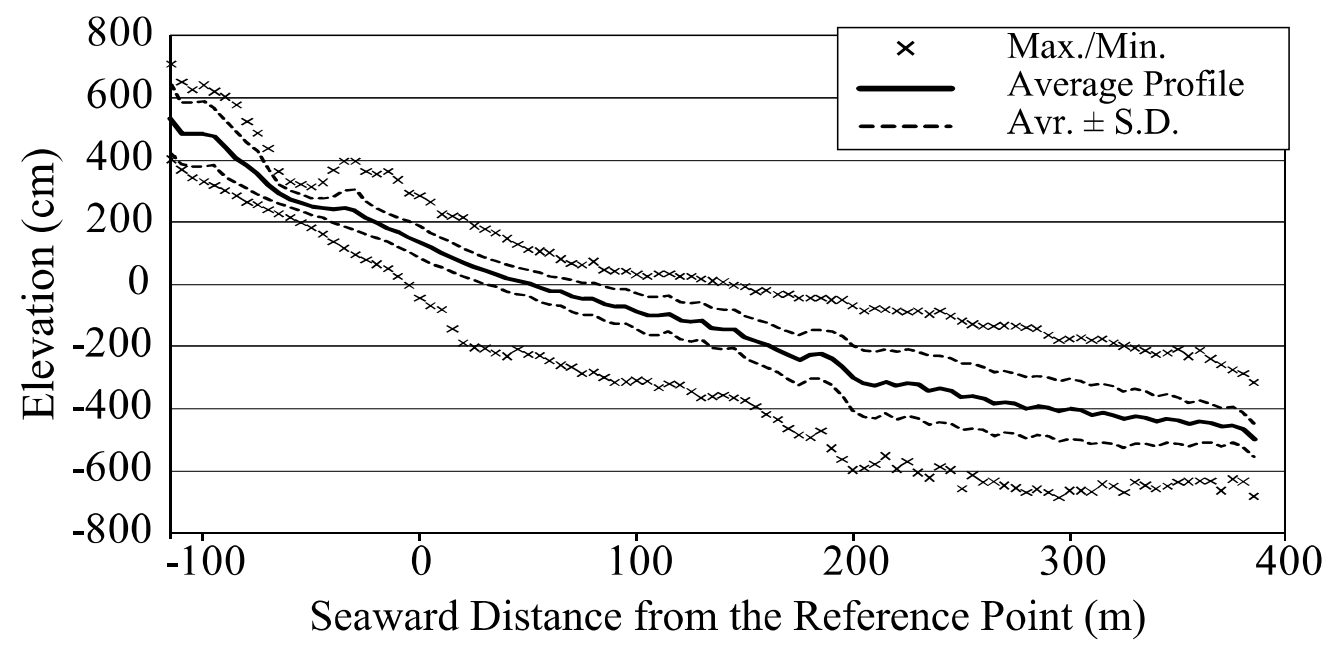

Figure 3. Average beach profile, standard deviations, and maximum and minimum elevations.

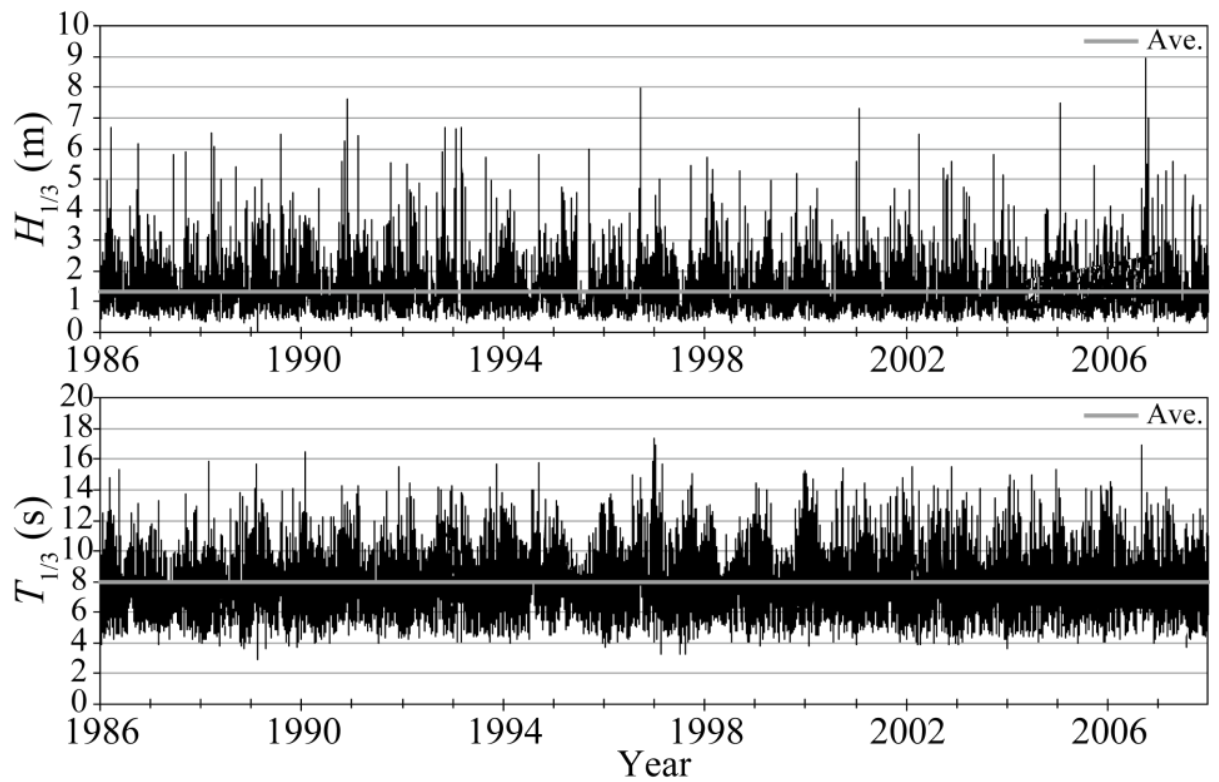

Figure 4. Offshore significant wave height and period at Hasaki. 


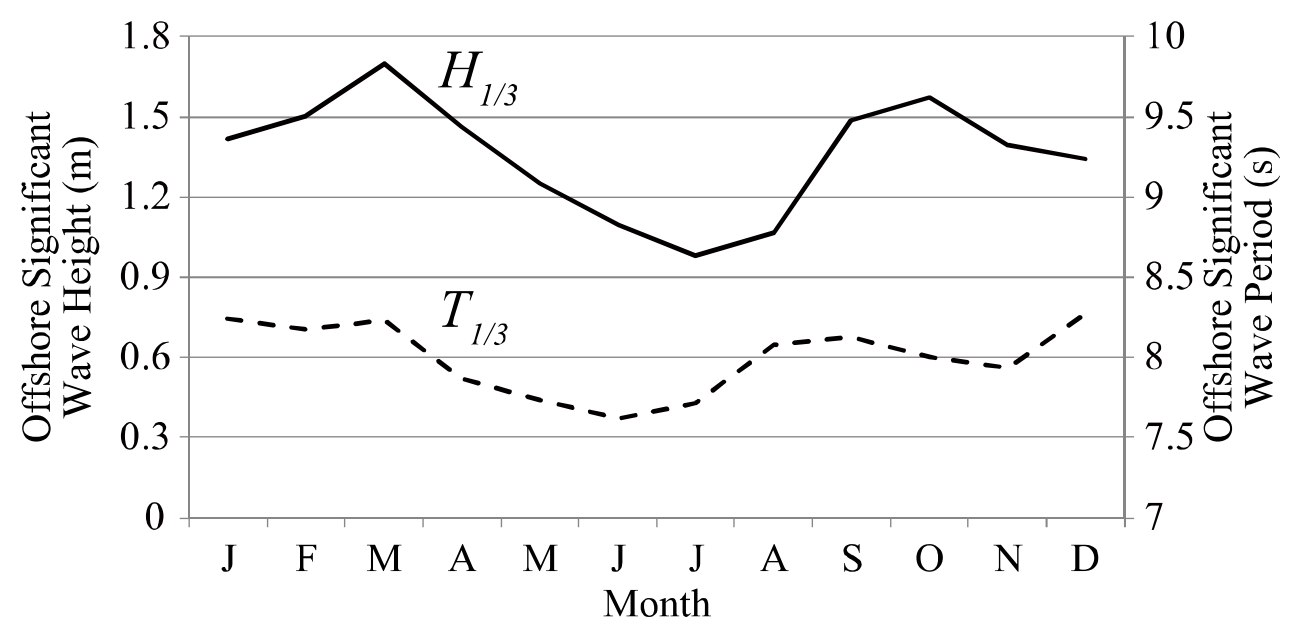

Figure 5. Monthly averaged offshore significant wave height and period at Hasaki.

\section{Multiple Regression Analysis}

In order to investigate the influences of bars and tides, a multiple regression analysis was used. The examined parameters which had the potential to affect shoreline change rates were offshore wave energy fluxes, previous shoreline positions, maximum, minimum and average tides, and inner and outer bar crest elevations. The parameters which affected the shoreline change rate were selected by comparing the candidate multiple regression models developed by combining the parameters on the basis of the Akaike Information Criterion (AIC, Akaike 1973) value. The selected parameters in the best model were thought to have effective contributions to shoreline changes. The value of AIC was calculated by the maximum log-likelihood and the number of free parameters (Akaike 1973) as follows:

$$
A I C=n(\ln 2 \pi+1)+n \ln \sigma^{2}+2(m+2)
$$

where $n$ is the number of data, $\sigma^{2}$ is the residual variance and $m$ is the number of free parameters.

The candidate models were developed by all possible combinations of the seven explanatory variables (the number of examined models was $2^{7}$ ). The objective variable is the shoreline change rate, and the explanatory variables include the parameters of waves, shoreline positions, bars and tides. The model containing all explanatory variables is expressed by:

$$
\frac{d y_{i}}{d t}=a_{0}+a_{1} E f+a_{2} y_{i-1}+a_{3} \eta_{\max }+a_{4} \eta_{\min }+a_{5} \eta_{a v e}+a_{6} z_{b 1}+a_{7} z_{b 2}
$$

where $a_{0}$ to $a_{7}$ are the partial regression coefficients, $E f$ is the offshore wave energy flux, $y$ is the current shoreline position, $\eta_{\max }, \eta_{\min }$ and $\eta_{\text {ave }}$ are the daily maximum, minimum and average tidal levels, respectively, and $z_{b 1}$ and $z_{b 2}$ are inner and outer bar crest elevations, respectively.

The temporal intervals were set at those of the beach profile survey, with which most data approximated daily data. In this study, among the data, only those data having temporal spans within 36 hours were used as daily data for estimating the parameter values and analyzing by the models, hence, the number of used data was 4359. The value of $E f$ was calculated from the wave heights and periods every 2 hours (Eq. 3), and daily averaged.

$$
E f=\frac{\rho g^{2} H_{1 / 3}^{2} T_{1 / 3}}{32 \pi}
$$

where $\rho$ is the seawater density, $H_{1 / 3}$ is the offshore significant wave height and $T_{1 / 3}$ is the offshore significant wave period. The inner and outer bar crest elevations were estimated as the maximum elevations in the regions where the seaward distances are $165-260 \mathrm{~m}$ and $265-365 \mathrm{~m}$, respectively (see Figure 2). The time series of the criterion and explanatory variables are shown in Figure 6. 

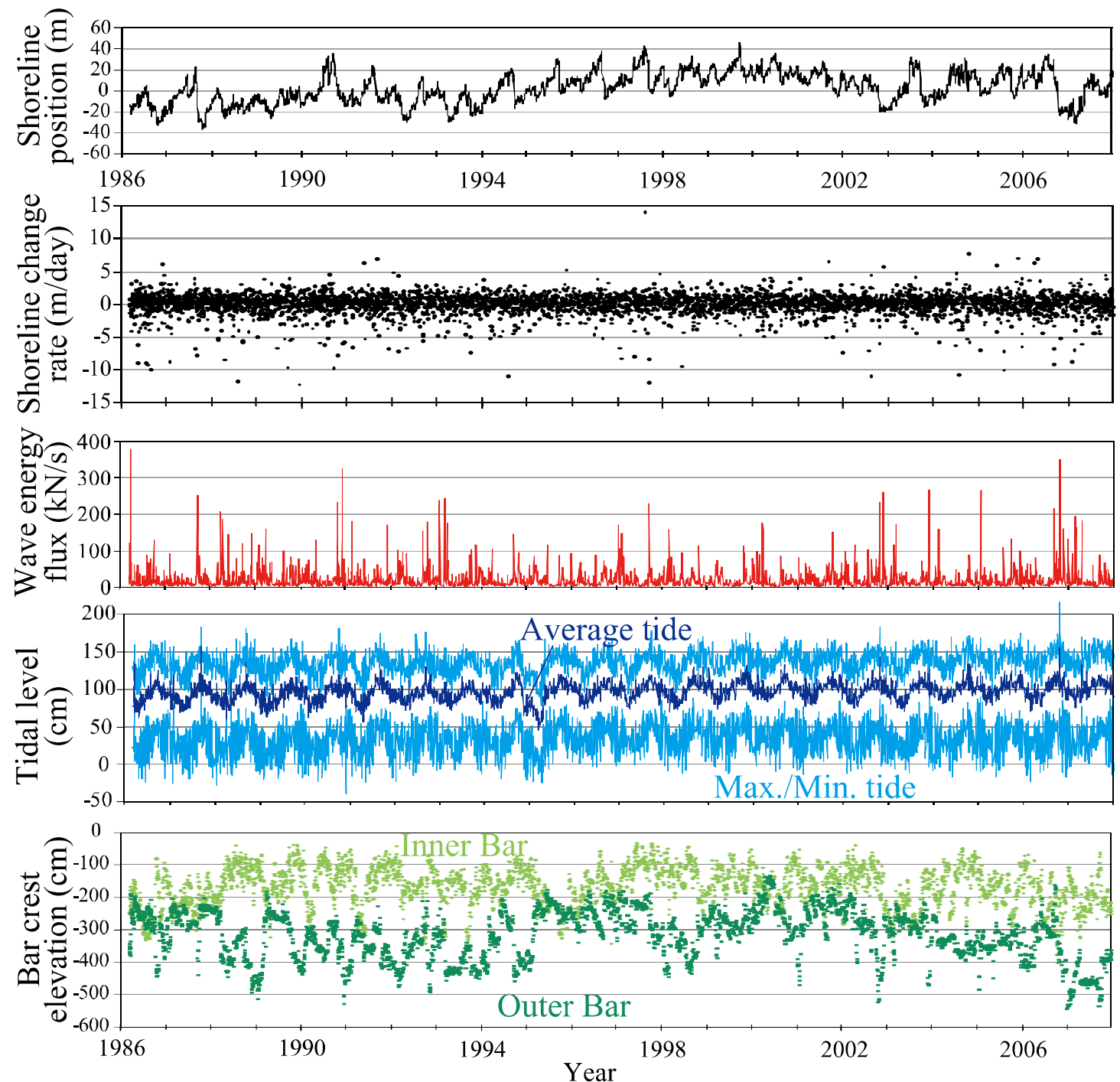

Figure 6. Time series data of shoreline positions, shoreline change rates, offshore wave energy fluxes, maximum, minimum and average tides, and inner and outer bar crest elevations.

\section{Correlations between Parameters}

If the correlations among the explanatory variables in a multiple regression model are high, the multicollinearity problem occurs. To avoid this problem, the combinations of parameters having a high correlation were not used concurrently in this study. Table 1 shows the correlation coefficients between the parameters. The correlation between $\eta_{\max }$ and $\eta_{\text {ave }}$, and that between $\eta_{\min }$ and $\eta_{\text {ave }}$ are relatively high, although the other correlations are relatively low. Hence, the model including the combination of $\eta_{\max }$ and $\eta_{\text {ave }}$ and that of $\eta_{\min }$ and $\eta_{\text {ave }}$ were excluded from the candidate models.

\begin{tabular}{|c|c|c|c|c|c|c|c|c|}
\hline \multicolumn{2}{|c|}{ Table 1. Correlation coefficients among parameters used for the analysis. } \\
\hline & $\mathrm{dy} / \mathrm{dt}$ & $\mathrm{Ef}$ & $\mathrm{y}$ & $\eta_{\max }$ & $\eta_{\min }$ & $\eta_{\mathrm{ave}}$ & $\mathrm{z}_{\mathrm{b} 1}$ & $\mathrm{z}_{\mathrm{b} 2}$ \\
\hline $\mathrm{dy} / \mathrm{dt}$ & 1 & -0.34 & -0.05 & -0.20 & -0.01 & -0.15 & 0.02 & 0.04 \\
$\mathrm{Ef}$ & & 1 & -0.15 & 0.17 & 0.12 & 0.20 & -0.05 & -0.09 \\
$\mathrm{y}$ & & & 1 & 0.20 & 0.15 & 0.26 & 0.16 & 0.30 \\
$\eta_{\max }$ & & & & 1 & 0.03 & 0.76 & 0.01 & -0.02 \\
$\eta_{\min }$ & & & & & 1 & 0.56 & 0.03 & 0.02 \\
$\eta_{\text {ave }}$ & & & & & & 1 & 0.04 & -0.01 \\
$\mathrm{z}_{\mathrm{b} 1}$ & & & & & & & 1 & -0.25 \\
$\mathrm{z}_{\mathrm{b} 2}$ & & & & & & & & 1 \\
\hline
\end{tabular}




\section{RESULTS}

The best multiple regression model, which had the smallest AIC, was the one including $E f, y, \eta_{\max }$, $\eta_{\min }, z_{b 1}$ and $z_{b 2}$ (No. 1 shown in Table 2). The correlation between the shoreline change rates obtained from the measurement and those calculated by the best models is shown in Figure 7. The multiple correlation coefficient was 0.38 .

For comparison, the model including only $E f$ and $y$ for the explanatory variables (No. 2) and the one with no explanatory variables (No. 3) are shown in Table 2. The AIC value of No. 1 was about 680 less than that of No. 3 and about 85 less than that of No. 2. This result confirmed that not only the wave energy fluxes and the shoreline position but also bars and tides contribute to the shoreline change.

Table 2. Partial regression coefficients of the model which indicated the smallest AIC (No.1), the one in
which only Ef and y were included as explanatory variables, and the one with no parameters.
\begin{tabular}{|c|c|c|c|c|c|c|c|c|c|}
\hline \multirow{2}{*}{ No. } & $\sigma^{2}$ & AIC & & $\mathrm{Ef}$ & $\mathrm{y}$ & $\eta_{\max }$ & $\eta_{\min }$ & $\mathrm{z}_{\mathrm{b} 1}$ & $\mathrm{z}_{\mathrm{b} 2}$ \\
\cline { 4 - 10 } & & $\mathrm{a}_{0}$ & $\mathrm{a}_{1}$ & $\mathrm{a}_{2}$ & $\mathrm{a}_{3}$ & $\mathrm{a}_{4}$ & $\mathrm{a}_{6}$ & $\mathrm{a}_{7}$ \\
\hline 1 & 2.38 & 3786.1 & 2.56 & $-2.07 \cdot 10^{-5}$ & $-1.21 \cdot 10^{-2}$ & $-1.35 \cdot 10^{-2}$ & $4.02 \cdot 10^{-3}$ & $7.75 \cdot 10^{-4}$ & $9.25 \cdot 10^{-4}$ \\
2 & 2.43 & 3871.4 & 0.45 & $-2.19 \cdot 10^{-5}$ & $-1.23 \cdot 10^{-2}$ & & & & \\
3 & 2.78 & 4466.9 & 0.02 & & & & & & \\
\hline
\end{tabular}

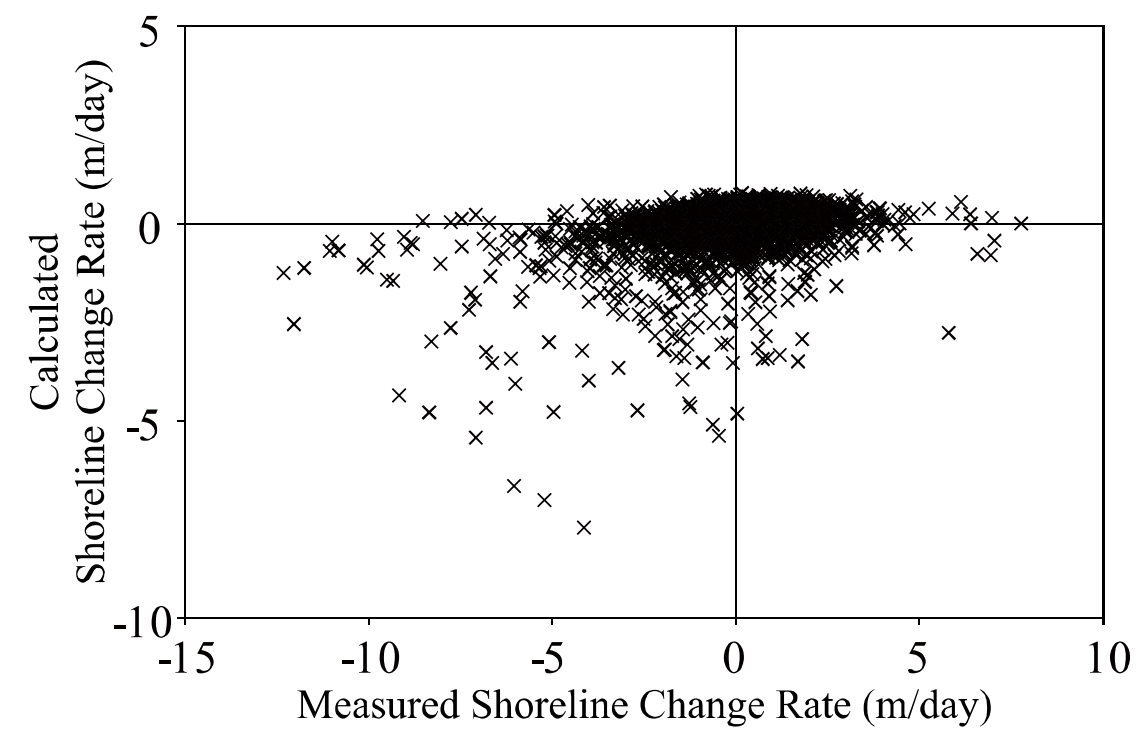

Figure 7. Correlation between the measured shoreline change rate and the calculated one.

To check the accuracy of the model, the shoreline positions were hindcasted by integrating the shoreline change rate estimated by the best multiple regression model. The shoreline position on 198603-12 was set as the initial value, and the time interval of calculation was 24 hours. The used data of Ef was daily averaged from 8 a.m. to 7 a.m. on the next day, and $\eta_{\max }$ and $\eta_{\min }$ were estimated as well. The shoreline position $y$ used for one of the explanatory variables was the calculated value on the previous day, and the bar crest elevations estimated from last measured beach profile were used as $z_{b 1}$ and $z_{b 2}$.

The shoreline position hindcasted by the best model (No. 1) agrees well with the measured ones (Figure 8). The root-mean-square error in the shoreline position is $12.1 \mathrm{~m}$ and the coefficient of determination $r^{2}$ is 0.36 . The shoreline position hindcasted by the one including only $E f$ and $y$ (No. 2) is also shown in Figure 8 for comparison. Especially, between 1995 and 2001, as the longshore bar developed more, the long-term shoreline advancement was expressed better by the best model than by the one without the parameters of bars and tides. This also indicates the importance of the parameters of bars and tides for not only the short-term like daily but also the long-term prediction of the shoreline change. 

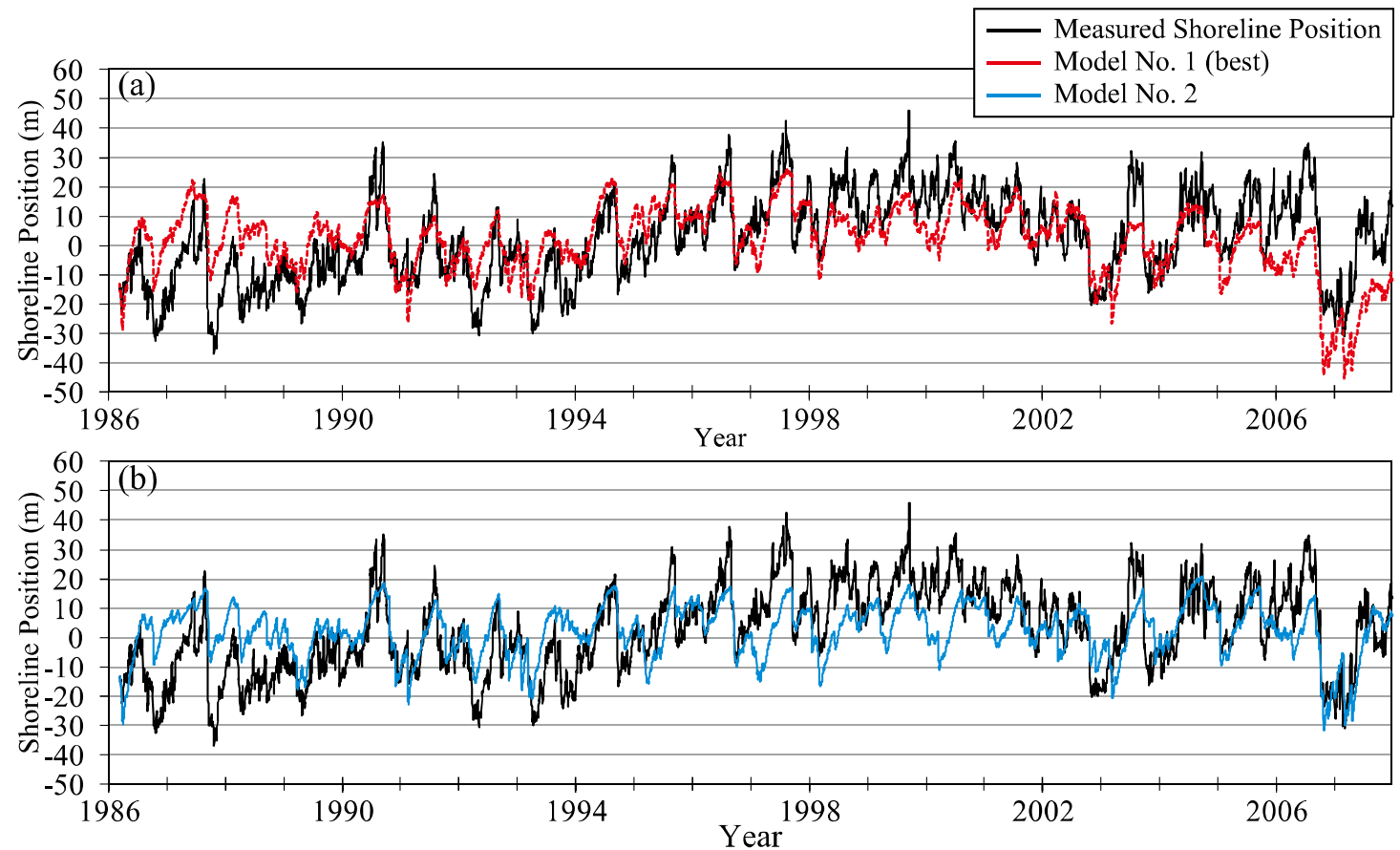

Figure 8. (a) Comparisons between the measured shoreline position and that hindcast by the best model including $\mathrm{Ef}, \mathrm{y}, \eta_{\max }, \eta_{\min }, \mathrm{z}_{\mathrm{b} 1}$ and $\mathrm{z}_{\mathrm{b} 2 \text {. }}$ (b) Comparison between the measured shoreline position and that hindcast by the model including only Ef and $y$ as the explanatory variables.

\section{DISCUSSION}

\section{Effect of Variables on Shoreline Changes}

The standardized partial regression coefficients (SPRC), which were defined by Eq. 4, show the relative importance of the explanatory variables (Table 3):

$$
a_{i}^{\prime}=a_{i} \cdot \sqrt{\frac{S_{i i}}{S_{Y}}} \quad(i=1,2, \cdots 7)
$$

where $a_{i}^{\prime}$ is the standardized partial regression coefficient, $a_{i}$ is the unstandardized partial regression coefficient, $S_{i i}$ is the variance of an explanatory variable and $S_{Y}$ is the variance of the objective variable.

The largest absolute value of the SPRC was the coefficient of $E f$, followed in order by those of $\eta_{\max }, y, \eta_{\min }, z_{b 2}$ and $z_{b 1}$ (Table 3). Although the parameters of tides were not explicitly included in previous shoreline change models such as Yates et al. (2009), Katoh and Yanagishima (1988), Davidson et al. (2010) and Miller and Dean (2004), $\eta_{\max }$ had the second highest effect for the shoreline change, which was more than one third of the effect of $E f$. The effect of the outer bar crest elevation is larger than that of the inner bar crest elevation.

\begin{tabular}{|c|c|c|c|c|c|}
\hline Ef & $y$ & $\eta_{\max }$ & $\eta_{\min }$ & $z_{b 1}$ & $\mathrm{z}_{\mathrm{b} 2}$ \\
\hline$a_{1}^{\prime}$ & $a_{2}{ }^{\prime}$ & $a_{3}{ }^{\prime}$ & $a_{4}^{\prime}$ & $a_{6}^{\prime}$ & $a_{7}^{\prime}$ \\
\hline-0.34 & -0.11 & -0.12 & 0.053 & 0.028 & 0.041 \\
\hline
\end{tabular}

The negative value of the coefficient for $E f$ shows that the shoreline retreats more as $E f$ increases, and the negative value of the coefficient for $y$ shows that the shoreline retreats more with more seaward shoreline position and advances more with more shoreward shoreline position. In addition to this result for $y$, although the simple correlation between $d y / d t$ and $y$ is low (see Table 1), the effect of $y$ is the third-largest explanatory variable. In other words, $y$ made a greater contribution in the multiple regression than in the single regression. Hence, $y$ is the suppressor variable (Horst 1941), and it is thought that $y$ has effects which tend to restore the shoreline to its original position from the great 
advanced/retreated position. These results are consistent with those previous studies (e.g. Yates et al. 2009).

The negative value of the coefficient for $\eta_{\max }$ shows that the shoreline retreats more as $\eta_{\max }$ increases. The positive values of the coefficients for $z_{b 1}$ and $z_{b 2}$ show that the shoreline retreats more as a bar develops less. These results are probably because waves break less at a higher tidal level or at a lower bar crest elevation, which results in smaller wave energy dissipation and so the erosion is increased (or the advancement is suppressed), and vice versa. At the higher tidal level, the berm is also eroded more easily by the higher wave run-up over and the shoreline tends to retreat.

The positive value of the coefficient for $\eta_{\min }$ indicates that the shoreline advances more as $\eta_{\min }$ increases. This tendency contradicts that for $\eta_{\max }$. Although the reason for the contradiction is not clear yet, it seems to be related to the tidal ranges. That is, $\eta_{\max }$ and $\eta_{\min }$ in the best multiple regression model can be transformed into the tidal ranges $\Delta \eta$ by:

$$
\begin{aligned}
& -1.35 \cdot 10^{-2} \eta_{\max }+4.02 \cdot 10^{-3} \eta_{\min } \\
& =\left(-1.35 \cdot 10^{-2}+4.02 \cdot 10^{-3}\right) \eta_{\max }-4.02 \cdot 10^{-3}\left(\eta_{\max }-\eta_{\min }\right) \\
& =-9.48 \cdot 10^{-3} \eta_{\max }-4.02 \cdot 10^{-3} \Delta \eta
\end{aligned}
$$

This shows that the shoreline retreats tend to be large on the spring tide and the shoreline advancements tend to be large on the neap tide. This is probably caused by the differences with temporal lag between the seawater levels and the ground water levels (e.g. Duncan 1964), giving rise to the seawater percolation resulting in deposition or the groundwater effluent resulting in erosion.

Multiple regression models were used for estimating the effects of bars and tides on shoreline changes in this study and the shoreline position hindcasted by the best model agrees well with the measured one. However, the relations between the shoreline change rate and some external forces are not linear in reality. For example, the shoreline change rate is zero when the offshore wave energy flux is zero and the shoreline advanced rate reaches a maximum in the state of slightly larger offshore wave energy flux than zero in reality (e.g. Sunamura 1983). The models used in this study cannot express such phenomena sufficiently. However, the models could be improved by incorporating physical processes, including the effect of not only wave energy fluxes but also bars and tides indicated in this study, without becoming extremely complicated.

\section{CONCLUSIONS}

The effects of bars and tides on shoreline change were investigated by multiple regression analysis. The analyzed shoreline data were obtained every workday during a 22-year period from 1986 to 2007 on the Hasaki coast in Japan. The examined parameters which had the potential to affect shoreline change rates were offshore wave energy fluxes, previous shoreline positions, maximum, minimum and average tides, and inner and outer bar crest elevations. In multiple regression analysis, parameters which affected the shoreline change rate were selected by comparing the multiple regression models developed by the combination of parameters on the basis of the AIC value, and the effects were also estimated by using the coefficients of the best model which had the smallest AIC. The results of this analysis are shown below.

The best multiple regression model which had the smallest AIC was the one including the offshore wave energy flux, the shoreline position, the daily maximum tide, the daily minimum tide and the outer and inner bar crest elevations. This result indicates that not only wave energy fluxes but also bars and tides affected the shoreline change rate. The offshore wave energy flux had the biggest effect on the shoreline change among the parameters, followed by the maximum tide, the previous shoreline position, the minimum tide, the outer bar crest elevation and the inner bar crest elevation, in order. The influence of the maximum tide on the shoreline change has more than one third of the effect of the wave energy flux. The reasons why the bars and the tides influence the shoreline changes are probably that waves break more and the wave energy dissipates more at a higher bar crest elevation and/or at a lower tidal level. At a higher tidal level, it is thought that the berm is also eroded more easily by the higher wave run-up over and the shoreline tends to retreat. 


\section{ACKNOWLEDGMENTS}

The offshore wave data at Hasaki were provided by the Ministry of Land, Infrastructure, Transport and Tourism. We would like to thank all the staff of HORS for measuring the beach profiles.

\section{REFERENCES}

Akaike, H. 1973. Information theory and an extension of the maximum likelihood principle, 2nd International Symposium on Information Theory, 267-281.

Davidson, M.A., Lewis, R.P. and Turner, I.L. 2010. Forecasting seasonal to multi-year shoreline change. Coastal Engineering, 57, 620-629.

Duncan, U.S. 1964. The effect of water table and tide cycle on swash-backwash sediment distribution and beach profile development, Marine Geology, 2, 186-197.

Horst, P. 1941. The role of the predictor variables which are independent of the criterion, Social Science Research Council, 48, 431-436.

Katoh, K., S. Yanagishima. 1988. Predictive model for daily changes of shoreline, Proceedings of $21^{\text {st }}$ International Conference on Coastal Engineering, ASCE, 1253-1264.

Kuriyama, Y. 2002. Medium-term bar behavior and associated sediment transport at Hasaki, Japan, $J$. Geophysical Research, 107, 3132.

Miller, J.A. and R.G. Dean. 2009. A simple new shoreline change model, Coastal Engineering, 51, 531-556.

Sunamura, T. 1983. A predictive model for shoreline changes on natural beaches caused by 253 storm and post-storm waves, Trans. Japanese Geomor. Union, 4, 1-10.

Yates, M.L., R.T. Guza and W.C. O'Reilly. 2009. Equilibrium shoreline response: Observations and modeling, Journal of Geophysical Research, 114, 1-16. 